\title{
BAER, BRIAN James \& KAINDL, KLaUs. QueERING Translation, Translating the Queer. Theory, Practice, ACtivism. NeW YoRK \& London, ROUTLEdGe, 2018, 234 PP., 9780367365677
}

This edited volume aims to be a comprehensive piece of work with a clear interdisciplinary approach that delves into a variety of topics thro ugh the lenses of translation, gender, sexuality, and identity. The chapters are distributed across three different sections, as prefaced in the book's title: theory, practice, and activism. The editors have carefully selected the chapters in order to provide a diverse portrayal of trans lation and gender from within a wide range of genres, such as narrative, essays, and the graphic arts as well as across different historical moments, territories and languages. This edited volume therefore manages to convey the great applicability of the queer approach to Translation Studies.

In Chapter 1, «Sexuality and Translation as Intimate Partners? Toward a Queer Turn in Rewriting Identities and Desires", Santaemilia provides a state-of-the-art chapter about the combination of two key disciplines: translation and sexuality. This interdisciplinary approach is currently gaining popularity in research. The discussion of the "queer» brings to the fore a series of topics that might be and have traditionally been overlooked. Translating sexuality has intrinsic political implications. By applying sexuality to the creation and analysis of translation, the intersection of matters around identities and their representation accompanies the discussion on queerness. Santaemilia thus proposes two main complementary perspectives: the translation of sexuality and the sexualisation of translation.

The former has traditionally been used since the 1990s, with sexuality being incorporated as an analytical category. This perspective is born out of the manifestation of sexuality in a text and how this is transferred into a different linguistic and cultural environment. The latter, on the other hand, is much more recent and is defined as a more complex task, involving greater documentation and evaluation to avoid biases. By apply ing sexuality to translation, the translator's understanding of certain conceptualisations about gender, sex, and moral norms are put into play. He invites research to take the queer turn, through the application of a queer-conscious perspective to research, a practice that is drawing the attention of queer researchers. This queer turn shows the potential of translation as a d oublepurposed practice: it problematises sexual id entities and leads to queer politics. Such exploration «brings translation into contact not only with issues 
of gender and sexuality but also with issues related to social class, race, ethnicity, and other factors linked to power asymmetries or ideology» (p.20).

In Chapter 2, «A Scene of Intimate Entanglements, or, Reckoning with the «Fuck» of Translation», by Basile, discusses the notion of intimacy in/with the text and its translation. In a very essayistic fashion, she delves into Spivak's understanding of translation as «the most intimate act of reading " (p.28) and pushes its boundaries to a raw definition of the quote. By means of an excerpt of Stephen's Je Nathanael in its original French version and its English counterpart, she aims to introduce the reader/critic to the space between text and translation. She aims to distance the reader from the subsequent analysis and discussion of the translation and invites the reader to explore what is being generated. She takes the translator out of the off-scene position in the act of translation and places them in the midst, in intimacy with a «fuckable text» (p.29).

Conceptualising the queer as a «discontinuous» and «navigable» space, Basile comments on the possibilities of this space between the text and the translator, expanding its reach beyond sensory attunement. This queer approach to translation is later linked to the name of the protagonist in the text Nathanael, which happens to be the name of the poet's author herself, who becomes an example of this space of continuous mutation proposed by Basile. She brings to the discussion the notions of embodiment and trans-embodiment, yet escaping from the transfer of one form to the other and focusing on the indeterminacy opened up in this irregular and mutable space of translation. In her words, the reader/critic is separated from the «linearities of before and after» (p.34) in translation, compelling us to explore the in-between.

In Chapter 3, «Beyond Either/Or Confronting the Fact of Translation in Global Sexuality Studies», Baer discusses the space of negotiation where the hegemony of the Western understanding of the gay and the queer is put to the test. Western values have culturally monopolised the rest of the world, but the issue is much more complex, which he exemplifies with the case of Russia and the Russian language. He combines the critique towards the homogenisation of the English-speaking understanding of the queer with the opportunities that such westernisation of the concept has brought to the members of the community.

By providing examples such as the act of "coming out» or the acquisition of rights (such as marriage), he confronts the global with the local and automatically places the English-speaking West in a position that, though hierarchically superior, is not always positive. The author sees translation as an opportunity to fracture and diversify minoritised approaches 
to the gay and queer. In Russian, the words gei [gay] and kvir [queer] show that, even if influenced by the hegemonical model in the community, there is a fragmented space with minoritarian models of homosexuality, thus destroying the ultimate binarism of «the West and the rest».

Chapter 4, «The Future is a Foreign Country. Translation and Temporal Critique in the Italian It Gets Better Project», by Bassi, tackles the localisation in Italian of an awareness campaign for the LGBTQ+ community. The project was disseminated through YouTube and the translation was open to volunteers who either self-identified as members of the community or shared common values. The author delves into the power of translation in the creation and recognition of queer narratives and experiences.

"Change» and «time» feature in the campaign that advocates for a better future without homophobia and transphobia, and the author shows how queering localisation can elicit other models of subjectivity. This piece of research explores this case study through the concepts of queer and activist translation and showcases the how the stories gathered in the project take distance from terms such as "gay» or "transgender» beyond their understanding in mainstream English.

In Chapter 5, «Ethnography and Queer Translation», Savci draws a very enriching parallel between translation and ethnography in which the linguistic dimension is viewed through an ethnographical lens. By applying theories from fields such as sociology and ethnography, she dismantles the traditional source and target binary that has dominated translation practice. Language is an ever-changing tool for humanity and ethnography and allows us to understand «narratives in practice» and what these mean to the «subjects that engage in them». She illustrates her ideas writing with examples extracted from the Turkish language and culture and highlights the asymmetrical power relations of cultures with Western languages as main producers and distributors of «desirable knowledge».

Savci provides evidence of how the same concept has different implications that go beyond the linguistic dimension, presenting language as a mutating entity within a mutating social environment. She explains how being pro-LGBT rights in Turkey opened a large discussion on what being in favour or against meant, how «rights» were understood, as well as the political meaning of supporting LGBT rights in that particular social and temporal context. In her conclusion, she advocates for an interd is ciplinary approach to Translation Studies, which can become the perfect space for understanding the combination of the verbal, the social and the textual, to help histo ricise and transnationalise languages. 
Chapter 6, «In All His Finery. Frederick Marryat's The Pacha of Many Tales as Drag ", St. André deals with the retranslation/pseudo-translation of early- $19^{\text {th }}$ century short story The Pacha of Many Tales based on the British East India Company director Francis Davis's translation of a Chinese play. The renewed short story is analysed from a drag translation point of view that allows for a new understanding of translation as an act of recreation and reproduction. The short story by Marryat, of a structure similar to the one found in the Arabian Nights, is a performative text full of stereotyping, exaggeration and orientalisation targeted at the British readership of that time. Such reproduction is discussed against the previous translation by Davis, which transferred the message more "faithfully» into the target language.

Through metaphor, as a way of shifting the attention from the translated text to the act of translation, meaning can be reconceptualised and reveals new underlying knowledge. The author proposes a cross identity performance approach that capitalises on the success of the performance including strategies such as passing or $d$ rag. This ap proach allows for a new reading of the relations between two cultures and the creation and continuation of discourses about the Other.

In Chapter 7, «Transgenderism in Japanese Manga as Radical Translation. The Journey to the West Goes to Japan», Chan analyses Japanese manga rewritings of Chinese traditional stories. In particular, the author explores how the classic The Journey to the West is altered and appropriated through what he calls «radical translation» (p.97). Through this practice, mid-way translation and adaptation, the characters and narratives in the original stories are queered to create new manga stories that include the change of gender of some of the characters and the diversification of sexualities that allow for the development of completely new plots and scenes.

Parody is the perfect environment for this transformative vision of translation that allows for a queerisation of the text. By utilising parody, radical translation can be more easily performed, allowing for the expos ure of «the true nature of notions unquestioningly accepted». He explores the transgendering and feminisation of male characters that takes place in general manga production, particularly in Boys' Love manga, which may be a response to the rigidity of gender binarism in Japanese culture. The chapter delves into a practice that has been done for centuries, viz. the reworking of Chinese traditional tales, from a queer angle.

In Chapter 8, «Speaking Silence and Silencing Speech. The Translations of Grand Duke Konstantin Romanov as Queer Writing », 
Tyulenev explores the poems, translations, and diaries of Tsar Nicholas I's grandson, whose nom de plume was K.R. and elaborates a queer reading of his work production. K.R. lived during the $19^{\text {th }}$ and $20^{\text {th }}$ centuries. He was a husband, and father to many children, yet he was not entirely satisfied with his monogamous heterosexual relationship as suggested in his writing. By performing a holistic and parallel close reading of both his diaries and his translations, the author identifies a process of homographesis, based on Edelman's theories, in which the homosexual identity is conceptualised. This process is revealed through the speech functioning qua silence and qua speech, following Sedgwick's epistemology, meaning that silence and speech can both reveal and conceal.

The analysis of the literary production of K.R. reveals a "closetedness" that may seem inexistent only by reading part of his works. His translations of Shakespeare, Schieller, von Engelhardt or Stecchetti and his own writing reveal that same-sex desire is present and portrayed openly. The analysis reveals the creation of a homosexual identity through the selection of texts to be translated and strategies such as gender omission or transf ormation in both translations and own writings.

In Chapter 9, «Translation's Queerness. Giovanni Bianchi and John Cleland. Writing Same-Sex Desire in the Eighteenth Century », Donato analyses an original novella by 18th-century author Giovanni Bianchi and Cleland's English translation of the same. In Breve storia della vita di Catterina Vizzani, Bianchi tells the story of a lesbian woman/transgender man who lived as both female and male during her/his lifetime. The analysis centres on the different take both authors had on the same life experiences. Donato argues and provides evidence of Cleland's moralising and judg mental approach to Vizzani's story, inexistant in the original, by showing the translator's additions and alterations present in the English text. This, she argues, proves that the translator aimed at a noble audience interested in an exotic Italian culture and Roman and Renaissance legacy, a place «of the sexually ambiguous, the exciting and the transgressive» (p.134).

Bianchi's novella is one of the few examples of female same-sex sexuality writings in the $18^{\text {th }}$ century. Through the examples provided by Donato, the Italian original text by Bianchi presents the queer as normal, while its English counterpart by Cleland is based on the presentation of the queer as depraved. This view filtered by Cleland promotes the idea of "negative branding» (p.140) of the queer in the target British audience, which has implications on the people's understanding of the translated source culture and context. 
In Chapter 10, «Literary Censorship and Homosexuality in KádárRegime Hungary and Estado Novo Portugal », Gombár proposes a very interesting approach to the investigation of censorship under dictato rial regimes, particularly in Communist Hungary and Salazar's Portugal. Her methodology is based on the analysis of English-original literary works whose translations were published in those countries. By doing res earch in this area, she aims to shed some light on the impact of the ideologies imposed by the dictatorships on the publication of such themes.

Based on Csehy's working methods, Gombár creates a vast corpus of Anglophone lesbian- and gay-themed literary works. She contras ted this corpus with the bibliographical records of published translations in the two countries between 1949 and 1974. Out of more than four hundred books, 24 were published in Hungary and 24 in Portugal. She also provides information found in some of the reports issued by reviewers, particularly in Hung ary, and highlights the ambivalence that existed in relation to attitu des towards certain publications. For example, in Communist Hungary some books were censored because they brought in ideas from the West, while some other books with «homosexual content» (p.147) were allowed in Portugal because of the international relevance of the author.

In Chapter 11, "On Three Modes of Translating Queer Literary Texts ", Démont puts forward a classification of translation strategies in three main modes adopted in the translation of literary texts deemed to show queer content. These strategies are based on the multilayered reality of queerness in literary texts that makes a unilateral approach to their translation impossible. These three modes are defined as misrecognis ing translation, minoritising translation, and queering translation. The first aims to hide queerness and just ignore it in the translation. In the second mode, the translation simplifies queerness to a unidimensional und erstanding by flattening out its connotative essence. Finally, the third mode highlights the queerness of a text by bringing to the surface its queer dimensions and hidden connotations therein.

As an instance of misrecognising translation, Démont analyses the Spanish translation of Walt Whitman's poems in which the translation fails to convey homosexual desire. Secondly, minoritizing translation is exemplified with an intralingual translation of François Villon's Ballades en jargon by Thierry Martin, which bares the already controversial title Ballades en argot homosexuel. Finally, the last mode, aimed at pinpointing the queer nature of a literary text by analysing the French translation by Jean Giono of Moby Dick. In such translation, two main strategies are proposed: the recovering of a suppressed content in previous translations and the reproduction of queerness in the translated text. 
In Chapter 12, «Queering Lexicography. Balancing Power Relations in Dictionaries", Nossem claims the relevance and responsibility of lexicographers as agents who shape the knowledge of a linguistic territory. The lexicographer is entitled to consider words and definitions worthy of documentation and including them in their work, e.g., a dictionary. She further analyses interlingual dictionaries which are based on equivalences and omit the ever-changing and multifaceted nature of languages. The wo rk of lexicographers, marked by objectivity, reinforces a normativity that seems too hegemonical and repetitive.

As a case in point, the words «gay», «queer» and «lesbian» are consulted in interlingual dictionaries for English, German, French and Italian. The equivalences provided proved to be partially exhaustive, since they only captured part of the language-specific meanings. By analysing said gaps, the author emphasises the decision-making power of lexicographers and concludes decisions depend greatly on external influences such as unconscious heteronormativity. Queering lexicography would challenge the structures of power and heteronormativity.

In Chapter 13, «Queer Translation as Performative and Affective Undoing. Translating Butler's Undoing Gender into Italian», Baldo discusses the impact and relevance of the retranslation of Butler's Undoing Gender into Italian. After focusing on Butler's original and its retranslation, Baldo discusses the consequences of such retranslation in the target country where it resulted in new debates and actions in the field of «gender" (used in the original English also in the Italian academic/activist sphere).

The author emphasises translation is seen as a performance, thus implying a creative task that results in a new text. The original text is a derivative of itself since everything is the repetition of something else, according to Butler. Baldo labels translation as precarious in the face of neoliberalist and fundamentalist ideas and claims that the queering potential of translating serves to challenge the perpetuation of certain conservative discourses revolving around sexuality and gender. In this sense, Butler's work needed to be undone in order to "effectively reach the Italian audience» (p.200).

Finally, in Chapter 14, "Years Yet Yesterday. Translating Art, Activism, and AIDS across the Visual and the Verbal», Smith discusses his artistic translation of Larry Kramer's 2004 speech The Tragedy of Today's Gays, concerning the gay culpability in the AIDS crisis. Addison Smith proposes a series of signs based on the charts us ed to diagnose colour blindness (which affects more men than women), in which three words for each letter of the alphabet are combined. Words are extracted from the 
original speech to display combinations of words that lead to interpretation and reflection.

The author draws upon Jakobson's theories of the types of translation - intralingual, interlingual and intersemiotic - and queers them to interrelate all of them to create his pieces by creating an illusory dismemberment between visual and verbal content. While the original verbal speech was displayed in a linear and clearly structured shape, the new pieces in the form of visual signs «become a cacophony of voices» (p.207) in a non-linear format. This big project of multimodal translation aims to highlight the powerful nature of Kramer's speech and aims to overwhelm the receiver by means of the repetition and combination of selected words.

In conclusion, this edited volume gathers a collection of interesting pieces of research in which gender and queer theories are made central within the field of translation. It showcases a collection of case studies that contribute to Translation Studies scholarship by queering the practice of translation or by analysing translation through a queer lens. Although research on translation and queerness is still scarce in our field today, this promising research avenue is gaining wider reputation and interest among scholars.

The variety in the selection of authors and topics discussed certainly provides a holistic understanding of the applications of queer theories to translation. There is a certain common pattern in most of the studies, which analyse translations under the queer magnifying glass. In these chapters, the practical application of a queer point of view definitely provides fruitful new knowledge and insights. However, there are other chapters in the book that, though interesting and certainly worth considering, differ from these practical cases found in most other chapters. These chapters revolve around concepts and in some cases by means of a rather too theoretical and philosophical approach. It is true that interdisciplinarity can be a great as set in this type of research. Nevertheless, a sense of unity and linearity (case studies with tangible conclusions, for instance) could have provided more cohesion and solidity to the collection. Despite the aforementioned criticism, this area opens up new avenues for interdisciplinary research that promotes not only new ground-breaking insights in Translation Studies but also rediscoveries of already well-researched topics from a different angle. Queering translation holds great potential for examining the connections between languages and cultures as well as for shedding light on power dynamics and hierarchies. This book therefore underpins the need for more research and analysis on this intersection of disciplines.

[GONZALO ITURREGUI-GALLARDO]

Hikma 20 (2) (2021), 443 - 450 